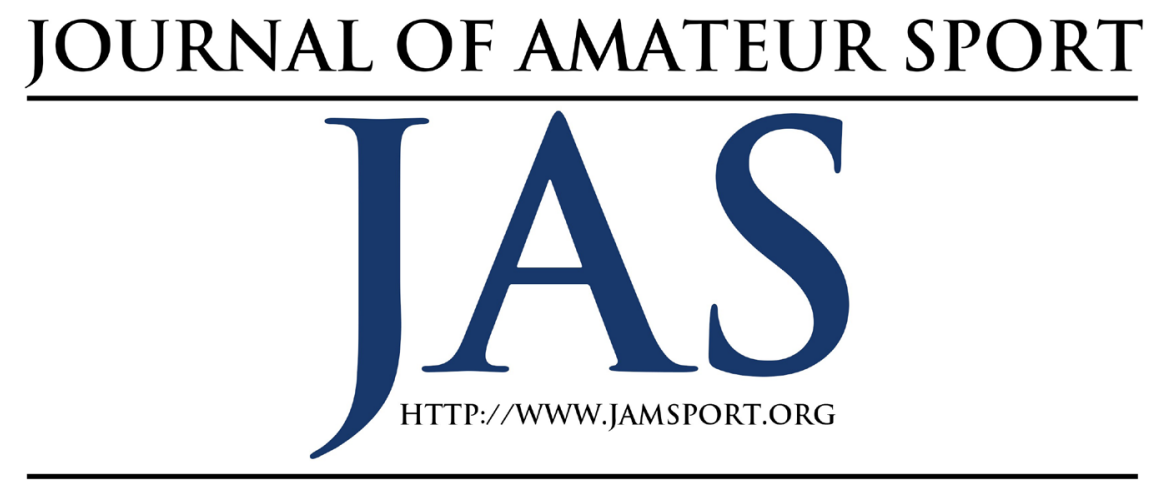

\title{
Harmonious or Conflicted? A Qualitative Study of Father-Coach and Daughter Relationships in Youth Sport
}

\author{
Isabel Ormond Nicholas L. Holt \\ Faculty of Kinesiology, Sport, and Recreation \\ University of Alberta
}

\begin{abstract}
Representatives of some Canadian sport organizations have called for more research with parent-coaches in order to inform policy and educational initiatives. The purpose of this study was to examine perceptions of relationships between father-coaches and their daughters. Sixteen participants (eight father-coaches and eight daughters) completed individual interviews, which were transcribed verbatim and subjected to a dyadic analysis. Four dyads were coded as harmonious and four dyads were coded as conflicted. Certain factors differentiated between the harmonious and conflicted dyads. For example, in the harmonious dyads father-coaches adopted a relationship-oriented coaching approach and were consistent in their behaviors between home and sport settings. In the conflicted dyads, father-coaches adopted a more intense coaching approach and behaved differently in home versus sport settings. Father-coaches in the conflicted dyads were also much harsher on their own daughters compared to father-coaches in the harmonious dyads. These differentiating factors offer guidance that may inform training and educational opportunities specifically geared toward parent-coaches.
\end{abstract}

$\mathrm{P}$ arent-coaches play an important role in amateur sport. Representatives of some Canadian sport organizations called for more research with parent-coaches in order to inform organizational policy and educational initiatives (Holt et al., 2018). Indeed, where- as some studies have shown there are positive aspects of having a parent-coach (e.g., strengthening parent-child relationships; Trussell, 2016), research also shows that the parent-coach and child relationship can be challenging, involving multiple sources of tension and conflict 
which may negatively impact children's experiences in sport (Eliasson, 2018; Jowett et al., 2007; Weiss \& Fretwell, 2005). Therefore, the purpose of this study is to examine perceptions of relationships between father-coaches and their daughters. Specifically, adopting an exploratory approach, this study seeks to identify factors that may differentiate between more positive and negative father-coach and daughter relationships.

In research examining (non-coach) sport parents, positive perceptions of parental involvement have been associated with increased sport enjoyment among children (e.g., McCarthy \& Jones, 2007). Alternatively, when parents over-emphasize winning and have unrealistic performance expectations, children may experience stress and reduced enjoyment of sport (e.g., Reeves et al., 2009). When parents are also coaches, parenting and coaching roles may become blurred (Holt \& Knight, 2014). For example, intrusive parental involvement as a coach may threaten children's privacy boundaries (Littlefield \& Larson-Casselton, 2009).

Researchers have asked children about their preferences for parental behavior in sport. Children want their (non-coach) parents to remain in control of their emotions, focus on effort rather than outcomes, encourage the entire team (Knight et al., 2011), and refrain from providing technical and tactical advice during competitions (Knight et al., 2010). Parent-coaches inevitably provide technical and tactical advice, so some of the behaviors children want from their parents may be at odds with the parent-coach role.
In fact, Schmid et al. (2015), who conducted a study with college tennis players who had been coached by their fathers, concluded that the benefits of having a father-coach were outweighed by the difficulties of effectively managing "blurred boundaries" (p. 233).

Considering the potential for the blurring of boundaries and role conflict, some Canadian sport organizations actively discourage parents from coaching their own children (e.g., BC Soccer Premier League, 2012). However, as parent-coaches play an important role in delivering youth sport in many countries (including Canada), discouraging parent-coaches would create an untenable situation. In light of the important influence of parents and coaches on children's sport experiences, and the potential challenges associated with parent-coaches, it seems particularly important to study relationships between parent-coaches and their children. Indeed, in Holt et al.'s (2018) study with 60 representatives of Canadian Provincial Sport Organizations, 42 participants called for more research on parenting, including parent-coach relationships. Understanding more about the (positive and negative) features of these relationships may reveal evidence that can be used to inform parent-coach education initiatives.

The current study also addresses certain methodological limitations in the existing parent-coach literature. Some studies (e.g., Elliott \& Drummond, 2017; Kerins et al., 2017) have included only parent-coaches themselves, and the perceptions of children within the par- 
ent-coach dynamic are less clearly understood. Furthermore, research has tended to focus on fathers or parents coaching boys (e.g., Elliott \& Drummond, 2017; Kerins et al., 2017; Weiss \& Fretwell, 2005). The perceptions of girls who are coached by their fathers have not been widely studied. Finally, with some notable exceptions (e.g., Jowett et al., 2007), studies have not included dyadic analysis that may account for variations in different types of parent-coach and child relationships. As a result, the current study used a qualitative description methodology (Sandelowski, 2000) to focus on daughters who were coached by their fathers and a dyadic analytic approach to explore and examine perceptions of relationships between father-coaches and their daughters.

\section{Conceptual Framework}

An inductive, exploratory, and data-driven approach was adopted to pursue the purpose of this study. Therefore, this study was guided by a conceptual framework rather than an explicit theory. Inductive approaches are compatible with the use of a conceptual framework (whereas deductive approaches may be more commonly used to explicitly test a theory or theoretical framework; Imenda, 2014). A conceptual framework can be understood as a way of organizing ideas to achieve the purpose of a research project, also guiding methodological (e.g., data collection and analysis) decisions (Shields \& Rangarajan, 2013). The conceptual framework for the current study was unpinned by previous empirical parent-coach research, along with conceptions of effective parenting and developmentally-focused coaching. Methodological decisions were guided by previous studies indicating the benefits of using dyadic analysis to examine parent-coach and child relationships (e.g., Jowett et al., 2007).

According to Maccoby (1999), relationships exist between people when their lives are interdependent, such that their behaviors, emotions, and thoughts are mutually interconnected. Qualitatively different types of relationships can emerge between parents and their children. For instance, close relationships are those that endure and involve frequent and diverse interconnections (Maccoby, 1999). Within the broader context of family life (e.g., in families with multiple children), parents can form dyadic relationships with each individual child. The term dyad implies bidirectional influences, and therefore the study of parent-child dyads can involve the consideration of behavioral, social, and affective interactions (Feldman, 2012).

The empirical literature shows there are both negative and positive aspects of the parent-coach and child relationship. Negative aspects of playing for a parent-coach include high pressure/expectations, criticism over mistakes, unfair behavior toward the child, and limiting recognition/displays of encouragement to avoid perceptions of favoritism from other parents (Elliott \& Drummond, 2017; Weiss \& Fretwell, 2005). Positive aspects of playing for a parent-coach include receiving perks, praise, more 
technical instruction, special attention, and being involved in decision-making (Weiss \& Fretwell, 2005). Hence, it may be possible to differentiate between more negative and more positive types of parent-coach and child relational dyads.

Conceptually, this study was guided by autonomy supportive and mastery approaches to parenting and coaching. Autonomy supportive parenting is a feature of sport parenting expertise (Harwood \& Knight, 2015) and exemplary sport parenting (Pynn et al., 2019). Autonomy supportive parenting is based on three dimensions (a) autonomy support versus control, (b) involvement, and (c) structure (Grolnick et al., 1991). Recent research (Holt et al., 2021) has shown that highly autonomy supportive sport parents engage in few controlling behaviors and promote autonomy by engaging in flexible conversations with their children and supporting their decision making. They create structure by setting boundaries and establishing clear expectations based on values, and are highly involved in their children's lives. Autonomy supportive parenting has been associated with positive outcomes such as increased self-determined motivation, sport satisfaction, and overall well-being (e.g., Amorose et al., 2016; Gagne, 2003).

We framed effective coaching from a developmental perspective. Specifically, we defined coaching effectiveness not in terms of improving performance, but rather as "the consistent application of integrated professional, interpersonal, and intrapersonal knowledge to improve athletes' competence, confidence, con- nection, and character in specific coaching contexts" (Côté \& Gilbert, 2009, p. 316). Furthermore, effective coaching is based on strong coach-athlete relationships (Jowett \& Arthur, 2019).

The conceptual framework also drove methodological components of this study. That is, a dyadic analytical approach was adopted based on insights provided from previous research. Jowett and colleagues (2007) interviewed six parent-coach/child dyads from the United Kingdom and identified two broad types of dyads; highly interdependent dyads and moderately interdependent dyads. Members of the two highly interdependent dyads perceived the parent-coach role as generally positive (e.g., the children described feeling supported and respected by their parent-coach). In contrast, members of the other four moderately interdependent dyads indicated more challenges (e.g., children feeling pressure to perform because they did not want to let their parents down).

A study conducted in Sweden sampled six parent-coach/child dyads (Eliasson, 2018). However, rather than using Jowett et al.'s (2007) dyadic analysis/profiling, only a thematic analysis was conducted. As such, results were presented at a group (i.e., thematic) level, and the unique characteristics of the particular dyadic relationships were not explored. Therefore, the results of the studies conducted by Jowett et al. (2007) and Eliasson (2018) suggest that recruiting dyads, and analyzing relationships within each dyad, could produce a nuanced understanding of father-coach and daughter 
relationships. We anticipated that it may be possible to identify different profiles of dyads, but were driven by data and did not determine profiles a priori.

\section{Method}

\section{Methodology}

As stated previously, a qualitative description methodology was used in this study. It is an applied research approach developed in the field of nursing that can be used to depict participants' perceptions of a phenomenon (Neergard et al., 2009). It is especially amenable to obtaining "straight" and "largely unadorned" answers "to questions of special relevance to practitioners and policy makers" (Sandelowski, 2000, p. 337). That is, from Sandelowski's (2000) perspective, the minimal theorizing associated with qualitative description is useful for describing events or phenomena, and such descriptions may be more useful for practitioners and policy-makers than heavily theoretical approaches. Qualitative description therefore uses a relatively low-interference approach and the results of studies are presented in a manner that stays close to participants' words rather than imposing abstract theoretical conceptions onto the data. Thus, in presenting a qualitative description study, the results should be practically applicable (Sandelowski, 2000, 2010).

\section{Researcher Positionality}

This study was underpinned by a relativist ontology and subjectivist epistemology (Lincoln et al., 2018). Ontologically, this philosophical perspective ac- knowledges that individuals' conceptions of social reality differ, but we assumed that it is possible to search for common patterns of shared perceptions among participants. Epistemologically, we assumed that knowledge is co-constructed between researchers and participants. Therefore, given the role researchers play in transforming, co-creating, and reproducing knowledge, it is useful to highlight features of the researchers' prior knowledge and experience that shaped the research process.

The lead researcher (a PhD student) identifies as a white woman and was an experienced and accomplished club, university, and provincial team coach. She was not a parent-coach. As such, she approached this study more from a coaching perspective than a parenting perspective. The co-researcher (a professor), a white man, was a club soccer coach and a father-coach at the time of the study. He holds a "conviction" (Thorne et al., 1997, p. 175) that endorses an autonomy-supportive approach in his parenting and coaching, and he views this as an ideal parenting and coaching style. Hence, we approached this research with some knowledge and experience (of parenting and coaching) but realized the importance of recognizing our biases and focused on the participants' unique experiences and perspectives. Furthermore, the differing perspectives of the two researchers allowed us to, at times, step back from the data to critically discuss and examine the analytic decisions. In particular, we strived to deliver a balanced summary of the themes that accounted for the children's perspec- 
tives that was not overly influenced by a pre-disposed 'positive' view of parents or parent-coaches.

\section{Participants and Recruitment}

Following Research Ethics Board approval, participants were recruited through criterion sampling (Patton, 2002). Fathers and daughters were targeted to address limitations of previous studies that have focused on fathers or parents coaching boys (e.g., Elliott \& Drummond, 2017; Kerins et al., 2017; Weiss \& Fretwell, 2005). To be eligible, parents must have been fathers who coached their own daughter for a minimum of one season. To recruit participants, an information letter was sent via e-mail to club/technical directors of local sport clubs, who were asked to forward it to coaches within their club who fit the sampling criteria. Eight father-coaches participated in the study, along with eight of their daughters. All participants were white and lived in two-parent households with at least two children. The average age of the fathers was 49.8 years ( $S D=5.7$ years), and they had coached their daughters for an average of 10.9 years $(S D=3.6$ years) in a range of team sports including hockey, soccer, basketball, and lacrosse. The average age of the daughters was 15.2 years (range 13-16 years, $S D=1.05$ years), and they had an average of 8.6 years $(S D=$ 3.3 years) of sporting experience.

\section{Data Collection}

Interviews. Data were collected through semi-structured, individual in- terviews (i.e., fathers and daughters were interviewed individually and separately). Within the semi-structured approach, participants are able, at times, to lead the pace and direction of the discussion, whereby the focus is on their own experiences and perspectives rather than asking questions in a particular sequence (Rubin \& Rubin, 2012). This approach was consistent with the ontological and epistemological assumptions underpinning this study (i.e., unique perceptions of social reality and co-construction of knowledge).

Interviews were scheduled at the participants' convenience and took place in a quiet location of their choice. Before conducting the interview, participants were given the study information letter, a verbal explanation of the study, and an opportunity to ask questions. Parents provided written informed consent for themselves and their children and the children provided oral assent. Following these pre-interview activities, the interviews were then recorded. The recorded portion of the interviews lasted approximately 45 minutes with father-coaches and 30 minutes with daughters.

Interviewer training. Prior to conducting the interviews, the lead researcher engaged in training, which included taking a graduate course in qualitative research methods and completing readings on how to conduct effective qualitative interviews. A practice interview was completed with another graduate student, who was otherwise unconnected with this study, to help the lead researcher develop her skills. 


\section{Interview guide development.} Two interview guides were created, one for children and one for father-coaches. The process of developing the interview guides began with the researchers brainstorming a list of potential open-ended questions. This list of questions was also informed by findings from previous research (e.g., Elliott \& Drummond, 2017; Jowett et al., 2007; Weiss \& Fretwell, 2005) to assist in developing specific ideas relevant to the research topic (Patton, 2002). The initial questions (and resultant interview guide) were discussed with other members of our lab team (i.e., senior graduate students). Following the guidelines provided by Rubin and Rubin (2012), the open-ended questions were then organized into categories of main questions, which were supplemented by follow-up questions, and probes. The open-ended main questions were designed to enable the participants to discuss their own experiences, and the follow-ups and probes were designed to encourage them to provide more detail as appropriate. Pilot interviews were completed with one parent-coach and one child who were otherwise unconnected to this study. In addition to providing interviewer training, the pilot interviews also served to further inform the interview guides (e.g., clarifying the framing of some open-ended main questions).

Interview guides. Prior to the onset of interviews, and reflecting on the ontological underpinnings of this study, the interviewer made it clear that there were no 'right or wrong' answers and the questions were designed for the participants to share their own experiences and perspectives. During the interviews, the interviewer was careful to follow the participants' lead and refrain from unduly imposing her own view of coaching.

For the fathers, questions included first asking them general questions about their coaching background and experience. Then they were asked two categories of main questions (focusing on their coaching perspective and parenting perspective). Questions in the coaching perspective category included: What can you tell me about the experience of coaching your daughter? How would you describe your expectations for your daughter? How do you feel your involvement in coaching your daughter has influenced her experience in sport? How do you treat your daughter in comparison to her teammates? How do you think your daughter is treated by her teammates? How do you think your daughter is treated by other parents of children on the team? Questions in the parenting category included: Can you tell me about your parenting style? How does it compare to your coaching style? How do you manage being a parent-coach in your family? Tell me about a time when the role of the coach conflicted with your role as a parent. Finally, they were asked if they had any advice for other parents who coach their own children.

Similar questions were used for the interviews with the daughters, but tailored to the daughters' experiences (e.g., how would you describe your father as a coach? What's your favorite story to tell about being coached by your dad? What has been the most difficult thing 
about being coached by your dad? Do you ever get the feeling that your parent treats you differently than your teammates?). Probes were used to engage the participants in conversation, which included using clarification statements (e.g., paraphrasing responses and asking for more information) and elaboration probes (e.g., Can you tell me more about that? Do you have any specific examples of that? What do you think your child/ parent would say about that?).

\section{Data Analysis}

Audio data were transcribed verbatim and checked with the original recording for accuracy. All participants were assigned a code (e.g., parent 1, child 1, parent 2, child 2). Dyadic analysis followed a data condensation approach (Miles \& Huberman, 1994; Miles et al., 2014), which involved selecting and simplifying data contained in the transcripts. Both researchers worked on the analysis collaboratively. The first step, in order to become familiar with the data and context for each dyad, involved the lead researcher reviewing the transcripts and creating short written summaries of the key features of each father-coach and daughter relationship. Then, working collaboratively, we returned to the transcripts for more detailed coding, which involved identifying and labelling themes and creating a coding scheme. For example, one of the identified themes was 'coaching approach.' For each dyad, we extracted and coded data from father and daughter transcripts that referred to the father's coaching approach. We eventu- ally complied all relevant data from each dyad into the theme coaching approach. Within each theme, the dyad data were kept together (i.e., quotes from father \#1 were followed by quotes from daughter \#1 and so on). This process was repeated until a complete list of themes, and accompanying data by dyad, was identified.

As each theme was being developed, rules of inclusion (i.e., descriptions of the theme meaning and the data coded therein) were written. As this coding process evolved, some of the initial themes were discarded or collapsed. For example, we initially had two 'sub' themes (favoritism and treatment from father). They were collapsed into one theme of treatment from father, because we decided that favoritism was an aspect of the daughters' treatment from their fathers rather than a distinct theme. The final coding was reviewed and agreed upon by both researchers.

The next step involved identifying similarities and differences among the dyads in relation to each of the themes. In order to achieve this, we created a data matrix. A data matrix is a visual representation tool that can facilitate the identification of patterns and themes across large amounts of data (e.g., an entire data set; Miles et al., 2014). The data matrix was in the form of a table. The columns of the table were each theme label and the rows were each dyad. Within each cell, we wrote notes to reflect the essence of the data coded within the theme. For example, some fathers adopted a more relationship-oriented coaching style, so we wrote "relational" in the cell for these 
dyads under the theme of coaching style. This was repeated for all themes and dyads until the data matrix was complete.

From here, we were able to visually inspect the data matrix to establish any patterns across the entire data set. At this point we discovered there were two clear groupings of dyads. We grouped the dyads in terms of whether the relationships were more "harmonious" or more "conflicted" (terms we selected in an attempt to characterize the core differences between the dyads). Four dyads (dyads 1, 4,6 , and 8 ) were classified as harmonious and four dyads (dyads 2, 3, 5, and 7) were classified as conflicted. Finally, we wrote a narrative account depicting the key similarities and differences between the harmonious and conflicted dyads on each theme.

\section{Methodological Rigor}

Neergaard et al. (2009) suggested that, for qualitative description studies, Milne and Oberle's (2005) guidelines for methodological rigor be used. These guidelines focus on authenticity and credibility, along with criticality and integrity. These concepts were integrated into the design of the study, as opposed to applying post-hoc 'verification' techniques. For instance, authenticity and credibility involved purposefully sampling an adequate number of participants and conducting a data-driven analysis that focused on participants' responses rather than pre-determined or theoretically derived concepts. This helped to establish an 'emic' perspective in which participants' perspectives are given 'voice' and that the researchers' (relatively low inference) interpretations are clearly tied to the participants' opinions. Furthermore, authenticity and credibility can be enhanced by probing for clarification and depth during interviews, accurate transcription, adopting an initial inductive approach, interviewer training and interview guide development, and understanding of context.

Criticality and integrity primarily involved reflecting on the role and influence of the researchers. One way this was addressed was by the lead researcher (who was also the interviewer) maintaining a reflexive journal, which included notes about her positionality coming into the study and throughout the research process (Berger, 2015). For instance, she made notes before and after interviews and during the analytic process. Another way we addressed credibility and integrity was via discussions between the two researchers. In this respect, it is relevant to reiterate that the lead researcher was an experienced coach while the co-researcher was a father-coach. The lead researcher tended to view the study as a coach whereas the other researcher tended to view the study as a parent (and parent-coach). These differing perspectives allowed us to, at times, step back from the data to critically discuss and examine the analytic decisions and presentation of data. Finally, the results were discussed with other members of the lab group at regular intervals, and they provided their perspectives and feedback, which facilitated further reflection. 


\section{Results}

\section{Coaching Approach}

There was a notable difference between the harmonious and conflicted dyads in terms of how the father-coaches' coaching approach was described. The father-coaches in the harmonious dyads were more relationship-oriented. The father-coaches in the conflicted dyads were described using terms such as loud, emotional, and intense.

With regard to the harmonious dyads, C1 said that her father's approach to coaching was that "he builds a relationship, a good relationship with [players] and with their families." Her father also described a relationship-oriented approach. He said, "I think in dealing with children, this is just maybe my philosophical approach, nothing should ever get in the way of the parent-child relationship, that is the most important relationship" (P1).

C4 (harmonious dyad) said that, as a coach, her father focused on "being a good person and not yelling." She further told us that he was "just generally a funny guy and people person" and noted that his coaching was on "a personal level with everyone." Her father also highlighted the emphasis he placed on relational aspects of sport. He explained that, "to me, the social aspects of them just having a fun place to meet with girls the same age, is as much important as the game itself" (P4). In another harmonious dyad, C6 explained that her father's approach to coaching was "to look for the best qualities in each player. He tries to look for the best in everybody... I think he's a good teacher." Similarly, C8 (harmonious dyad) said that her father "always tries to be more personal with the kids, joke around... He tries to get to know the girls... He's just not really an emotional kind of coach."

In contrast, the fathers in the conflicted dyads were not described in such relational terms. For example, C2 (conflicted dyad) described her father-coach as "loud. On the sidelines... He's loud. He is very opinionated" and she said that: He used to get a lot of technicals [technical fouls for arguing with a referee] when I was in younger age groups and I didn't like that... I just hated seeing him angry. I hated it more than anything, seeing my dad angry, that was so upsetting to me for the longest time. C3 (conflicted dyad) said that her father-coach "can be pretty scary sometimes. Like really, really loud... He can get kinda mad, like, if you do something or really mess up, he gets kind of mad." Her father agreed that he was an intense coach and said this was "because I probably take it a little more seriously or feel it a little more intimately than someone who never played the game" (P3). C5 (conflicted dyad) said her father "get[s] mad if someone does something wrong." Her father told us that, "I probably get a little too emotional in that respect" (P5). Similarly, C7 (conflicted dyad) described her father as being "tough on us and rough." Her father explained that he took a tough approach because "it's more fun winning than losing, that's just the 
facts, right?... We all like to win. I'm not going to BS anybody about that" (P7).

\section{Parent and Coach Role}

This theme depicts ways in which fathers approached the parent and coach roles. In the harmonious dyads it seemed that the fathers were fairly consistent in their behaviors as a parent (in the home setting) and as a coach (in the sport setting). There appeared to be far less consistency between home and sport settings among fathers in the conflicted dyads.

For example, when we asked C4 (harmonious dyad) if her father was different at home versus at sport when he was coaching, she said "not really... Personality wise and attitude wise, it's pretty similar." Her father explained that "I don't really think I change my thoughts or think from parenting to coaching, it's pretty similar... Just because it's consistent" (P4). Similarly, C8 (harmonious dyad) said that her father was "pretty much the same to me. He's pretty much the same" as a coach and as a parent. She then paused for a moment of reflection during the interview, and said, "that's interesting. To me it's always just dad. That's just dad. I never thought of him as coach."

In contrast, some participants in the conflicted dyads noticed inconsistencies between their fathers as a parent and as a coach. C2 noted differences between her father at home and at sport. She said, "he doesn't really goof around when it comes to coaching or being intense in a game situation. He's very in the moment all the time so that changes from that atmosphere of being in a game or being at home." Indeed, her father said "It's hard to turn it off, as a dad coach" (P2). C5 (conflicted dyad) said that the consistency between her father as a coach and as a parent "kind of just depends on the day. If he's having a good day or a bad day." She continued, telling us that "if he's nice to me at home, he'll always be nice to me on the court." Interestingly, her father said "I've never really thought about it in terms of difference between being a parent as such and being the coach or being a parent-coach" (P5). P3 (conflicted dyad) readily acknowledged he was different as a parent versus as a coach. He said that when he's the coach "I'm the coach for everybody. I'm not there to be your dad right now... I just switch off, just go into coach mode." Another father from a conflicted dyad told us that, "I haven't had to be a parent over a coach... For me when the head coach hat goes on, the team comes first" (P7).

\section{Treatment from Father-Coach}

This theme concerns the ways in which the father-coaches treated their children in the sporting environment. We found that across all the dyads there were examples of the daughter being treated differently by the father-coaches in comparison to how the father-coaches treated their daughter's teammates. Reports of differential treatment seemed much more challenging for the daughters in the conflicted dyads compared to those in the harmonious dyads.

For example, C1 (harmonious dyad) told us that "there were a lot of times 
when even if I was the top player on the team he wouldn't start me in games." But she also said, "my dad will talk to me about it. And tell me. So, I was okay with it. And when it got to more meaningful games, then he would start me." C1's father said he would not start her in easy games to "avoid the optics of nepotism" (P1). He pointed out that "she'd still get as many if not more minutes than everybody else, but [not starting her] was just an easier way of avoiding the problem" (P1).

C6 (harmonious dyad) said "no, not really. No" and "I don't think he treated me differently than the other girls" when we asked if her father treated her differently to her teammates. Similarly, in another harmonious dyad, C8 said her father "never favored me [and] he's never hard on me." Her father said that he strived to "treat your kid like everyone else. It's hard to do, but you have to" (P8). When we asked C4 (harmonious dyad) if she ever felt that her father treats her differently to other teammates, she said, "not really" other than asking for her input when he was planning practices. At first, her father told us that he did not "expect more" from C4. But then went on to clarify this statement, explaining that, "I probably do expect more from them in terms of fair play... but that's probably whether I was the coach or not" (P4).

We also found that fathers tended to treat their daughters differently to teammates in the conflicted dyads, but the ways in which the treatment was described was much "harsher" than in the harmonious dyads. For instance, C2 (conflicted dyad) said her father "definitely ripped on me more" compared to her teammates. She continued, explaining that if she made a mistake "he definitely got on me more than everybody else." When we asked her father if he treated his daughter any differently to her teammates he said, "of course" and noted that although "it may not necessarily be fair, [she is] still going to benefit from it" (P2).

Similarly, C3 (conflicted dyad) said that her father "goes a lot harder on me.... He said he expects more out of me and so he goes harder on me." Her father readily acknowledged he treated his daughter differently. He said, "quite often I would use her as a medium to get a message to the team if I was really getting frustrated... If I felt like I had to drive it home, I would drive it home through my daughter" (P3). He thought "she understood that" and that "she was OK with it." Yet, he later said that his children would sometimes say "why does it always got to be me?" and he would normally respond "Well because I'm your dad and I said so." He justified his behavior by saying, "I don't want them to ever be accused of favoritism so it was probably inequitably hard on them at times."

This notion of being harder on one's own child was consistent across the other conflicted dyads. C5 said, "I think that he's being harsher on me. So, if basically I do something wrong, say wrong, and if I miss a basket or anything... I feel that he is harsher on me." C7 (conflicted dyad) said, "he's harder on me... He 
always goes after stuff more with me if I do something wrong." Her father confirmed that his daughter "get[s] treated harder. And I know that there's a bigger expectation of [her] to practice hard and work harder" (P7).

\section{Treatment from Teammates}

This theme refers to daughters being treated differently by their teammates as a consequence of being the coach's daughter. Members of three harmonious dyads (Dyad 1, 6, and 8) did not think the daughter received any different treatment from her teammates. The exception was harmonious dyad 4. C4 explained that, by virtue of her being the coach's daughter, teammates would ask her for information or ask her to pass on a message. C4 said that "one girl in my class" at school (who also played on the team) would often say "hey, can you tell your dad this?" Her father also recognized this, and said teammates would ask his daughter "things like 'when's practice?' Or "why did we do that at practice?"' But P4 recognized there may be consequences to treating his daughter as a messenger. He said, "It's a casual question for them, and [they] don't realize the pressure that might put on her."

All four children in the conflicted dyads said they received distinctly different treatment from their teammates because their father was the coach. C2 (conflicted dyad) said that "your relationships with your peers gets strained. If your dad says something to a teammate it affects your relationship a little bit... That was probably the hardest part about it." Her father acknowledged that "I know she has struggled with it... She lost friends on the team" (P2). C3 (conflicted dyad) said her teammates "sometimes get really mad at me... They kind of get jealous for some reason." When we asked her father if he thought his daughter got treated differently by her teammates because he was the coach, he was unsure. P3 waivered, saying, "I don't think so. They might I think. I don't think so." C5 (conflicted dyad) told us about a time when her teammates did not like her father as the coach. She recalled "they were talking bad things about him." C7 (conflicted dyad) told us about a problem she encountered. She said:

There were two teammates...

They had the influence of their parents fighting with my dad so they kind of thought that they had to be like their parents and just ignore me... There was a lot of attitude that was coming from some players on my team.

As a result of that experience, $\mathrm{C} 7$ said "we actually moved to a different hockey team. Just so we wouldn't have more conflicts with them."

\section{Treatment from Other Parents}

This theme refers to the daughter being treated differently by other parents on a team because she was the coach's daughter. No children or father-coaches from the harmonious dyads reported any examples of this. In fact, C1 (harmonious dyad) said she and her father "have had those conversations [about other parents treating her differently]. He's 
always been worried about that I think." But P1 did not report any concerns.

The experiences of children in the conflicted dyads stood out in stark contrast. C2 (conflicted dyad) said that one season the parents of some of her teammates had "an attitude" toward her and "just kind of tension." She went on to say that "parents talk to their kids about that." Her father did not recognize his daughter's experience. Referring to his decisions to give her the ball at the end of games, P2 said "I was really lucky... there's never been any doubt" from other parents. P3 (conflicted dyad) said "there's always one or two parents who are kind of a little brown nosey to the coach's daughter." When discussing the previous season, C7 (conflicted dyad) said:

... there was a lot of problems with parents last year and there was lots of fights. It was really bad. Whenever they saw me, they never talked to me or said "hi" or anything after games or before games.... It kind of annoyed me. I didn't do anything and it was annoying that they were avoiding me.

\section{Car Ride Home}

This theme refers to father-coaches engaging in coaching their children beyond practice or game settings. We found these "extended coaching activities" occurred in all the dyads. It could include talking about the sport at home or doing extra drills outside of practice. But of the most widely discussed topic in this regard was the car ride home.

For example, in dyad 4 (harmonious), the daughter would discuss games in the car ride home and explained that sometimes she could be rather negative. In these cases, her father would end the conversation. She described a time when, "I was complaining about one thing, and then he was like 'okay it's been ten minutes. We get it. Put the reins on."' (C4). Her father explained that his perspective was "As a parent you're just saying it's 'OK, let it go, we've walked off the field now.' So trying to teach her that" (P4). In a similar vein, C6 said that her father was quite calming during the car ride home. She said, "yeah, there's less stress when you're coming home. You might move on from the subject." She also told us, "I really enjoy that time." Her father said that if his daughter "look[s] for advice then I tend to give it. I try not to give too much unsolicited advice" (P6).

C8 (harmonious dyad) said that during the car ride home "I like talking about it [a game] ... We just like talking about it. But when you get home it's done. It doesn't matter anymore" and that "it's usually me talking more." She said that her father is "not really forceful. He gives his opinion, I give my opinion. He's not going on a rant... my dad's pretty laid back." Her father provided a similar perspective. He said, "once we get home, I don't really talk that much about the game... we talked about it. You can't really belabor the subject" (P8).

Participants in the conflicted dyads also talked about the car ride home, but generally, there seemed to be a different tone to these conversations. C2 (conflicted dyad) said "on the way home it's never silent in the car. We're always talking about what happened here, what hap- 
pened here, what happened here. And I get annoyed sometimes." She went on to say:

I hear it over and over again and I don't want to talk about it anymore... I just have to tell him. I can't just ignore him because then he's like 'I know what I'm talking about, just listen to me.' And I'm like 'but I've been listening.' Her father, P2, rationalized this by explaining that he was coached by his own father and they routinely talked about the game in the car ("it was just how it was, right?"). Discussing his interactions with his daughter in the car ride, he said:

You go home from the game talking about the game. I think everybody looks at that in a negative light, and I'm sure there were times with me when I was just like rah, enough, enough dad, no more. But I think that molds you into a cerebral player.

But he continued, explaining that he would sometimes notice his daughter "rolling the eyes or something like that. And I'm just like 'oh shit, what's happened?' It's got away." Yet, he concluded this segment by saying "that's never going to stop, talking the game and that's, just like I said, it's part of being part of our family" (P2).

P3 (conflicted dyad) said of the car ride home:

There are times when they are legitimately upset about something... Whereas they'll be quite interested in dissecting the whole problem with me and wanting my feedback... So, I mean the level of connection that we have is a double-edged sword.

C5 (conflicted dyad) said "especially after a game, on the car ride home, we usually talk about the game and good things that we did throughout the game and not so good things or things we need to improve on or work on." Her father said "we talk about a lot of other things too it's not only sport, it's many other things too." Finally, C7 (conflicted dyad) said she had learned the importance of "just trying to play my hardest so I don't have a lecture about what I have to work on the way home from the game. [And] it comes after bad games. He tells me I did wrong..."

\section{Quality Time/Bonding}

All the fathers and two of the children from the harmonious dyads said that sport provided opportunities for them to spend quality time together as a family, which helped with their father-daughter bond. Discussing her experience playing on a team her father coached, C1 (harmonious dyad) said "I think being able to experience that with him was really fun." Her father said "me coaching is just quality time to spend with my kids" (P1). C6 (harmonious dyad) said, "we get to both experience the craziest moments together. ... You have a strong connection." She went on to say "it kind of like brings you together and it's a good way of bonding." Her father said:

It's one of the areas that we have in common that we can, you know, 
talk about outside of other life activities. ... It's been pretty positive experience that gives us something to talk about and do together... I think it's a good way to be in contact with your kids all the time (P6).

Two children (C2 and C3) and two fathers (P5 and P7) from the conflicted dyads also highlighted the benefits of spending quality time together and bonding (although it was interesting to note that no child or parent from the same dyad reported this). These comments were consistent with comments made by the harmonious dyads. For example, P7 (conflicted dyad) said "It's a change for me to be with them and be closer to them and develop our bond even more." There was, however, one unusual instance of quality time and bonding in the conflicted dyads. C2 (conflicted dyad) said:

I think it brings you closer. Like I said, he's my best friend and that's because I've been yelled at him. For many different reasons. For home reasons and for basketball reasons and I'm used to it. And then, after he yells at me we can laugh about it. So, it really creates a bond that is irreplaceable.

\section{Enjoyment}

All the father-coaches and children from the four harmonious dyads reported their experience as being enjoyable. C1 (harmonious dyad) said, "I loved my dad coaching me. It was a different experience and I just really liked it." Her father also had an enjoyable experience, saying "It's been very positive and I would have no hesitation doing it again" (P1). C4 (harmonious dyad) said, "I like it when he's the head coach" and her father said his coaching experience was "awesome" and that he enjoyed coaching "not just with my daughters, but with all the girls and the teams" (P4). C6 (harmonious dyad) said "I actually enjoy having him as a coach." Her father said coaching had been "a positive experience... I've enjoyed it a lot" (P6). C8 (harmonious dyad) said that her most recent season "was fun because my dad was my head coach." Her father said his experience coaching has been "very positive. I mean, I don't know why more people don't do it... I think it's a lot more fulfilling" (P8).

In contrast, no children from the conflicted dyads reported enjoyment. Yet all four fathers from the conflicted dyads said they found the experience enjoyable. For instance, P5 (conflicted dyad) talked about how much he enjoyed the experience and said "Yeah, I wouldn't trade it for the world." Somewhat tellingly perhaps, P3 (conflicted dyad) said "I probably enjoyed it more than they did."

\section{Discussion}

The purpose of this study was to examine perceptions of relationships between father-coaches and their daughters. The dyadic analysis resulted in the identification of harmonious and conflicted dyads. There were some markedly different features of the father-coach and daughter relationship between the 
harmonious and conflicted dyads. These differences offer unique contributions to the literature by articulating some of the factors that may influence, and differentiate between, the nature of the more positive (i.e., harmonious) and negative (i.e., conflicted) father-coach and daughter relationships. Specifically, the identified themes provide insights into factors associated with more positive types of relationships, which may offer practical guidance for improving father-coach and daughter relationships in sport and informing coach education initiatives for parent-coaches.

Previous studies have revealed both positive (e.g., children receiving special attention, praise, and being involved in decision-making) and negative features (e.g., control, harsher criticism) of parent-coaching (Elliott \& Drummond, 2017; Kerins et al., 2017; Schmid et al., 2015; Weiss \& Fretwell, 2005). These previous studies have provided few insights into how and why there are (seemingly contradictory) positive and negative outcomes of parent-coaching. The results reported in the current study did not reveal contradictions; they revealed that the father-coach and daughter relationship differed between dyads. For instance, we did not find that father-coaches were simultaneously harder on their own child while also giving them special treatment (a contradiction). We found that some dyads reported features of the relationship (e.g., different treatment from teammates in conflicted families) whereas other dyads did not. We may have identified relational factors that contribute to positive (and/or negative) outcomes among father-coaches and their daughters. That is, some of the factors that differentiated between the dyads may represent ways to improve father-coach and daughter relationships and, in turn, improve the developmental experiences daughters of father-coaches accrue from their participation in sport.

Our findings showed distinct differences in the coaching approaches adopted by fathers in the harmonious and conflicted dyads. For example, in the harmonious dyads, father-coaches adopted a relationship-oriented coaching approach, whereas in the conflicted dyads, father-coaches adopted a more intense coaching approach. Mastery, autonomy supportive, and transformational coaching styles have been associated with a range of positive outcomes in sport (Vella \& Perlman, 2014). Likewise, authoritative and autonomy supportive parenting styles have been associated with positive outcomes such as increased self-determined motivation, sport satisfaction, and overall well-being (e.g., Amorose et al., 2016; Gagne, 2003). An implication is that relationship-oriented coaching approaches (and, potentially, autonomy supportive parenting styles) may help improve relationships between father-coaches and their daughters. Although plausible, it should be noted that this is a speculative interpretation arising from our exploratory study and in the future it would be necessary to assess coaching and parenting styles among parent-coaches and their effects on developmental outcomes for children. 
Rather than showing the blurring of boundaries (Schmid et al., 2015) or impracticality of separating the parent and coach role (Zehntner et al., 2019), our analysis focused on the consistency of the fathers' behaviors in their role as a parent (in the home setting) and as a coach (in the sport setting). We found that fathers in the harmonious dyads tended to be consistent between home and sport. Previous research has highlighted the critical importance of consistency in parenting for supporting positive outcomes among children (Lippold et al., 2016). It may be that, in focusing on roles or general themes rather than behaviors across different settings, previous work has overlooked the matter of consistency and inconsistency in parental behaviors between sport and home.

A robust finding from previous research is that the children of parent-coaches receive different treatment from their parent-coaches (e.g., intentional criticism, harsher feedback, higher expectations) to avoid perceptions of favoritism (Eliasson, 2018; Elliott \& Drummond, 2017; Schmid et al., 2015; Weiss \& Fretwell, 2005). The current results further corroborate these results for the conflicted dyads. Even in the harmonious dyads there were examples of treating one's own child differently to teammates. It perhaps seems inevitable that parent-coaches will treat their children differently to other teammates, but they can nonetheless engage in specific behaviors (e.g., manipulating starting role, expectations around fair play) that seem less harsh and abusive than those apparent among the conflicted dyads in the current study. By capturing differences between father-coaches' behaviors in harmonious versus conflicted dyads, the results of the current study offer a new contribution to the literature. Specifically, they highlight that, even when treating one's own daughter differently, it is possible to do so in ways that are not perceived (by children) as being harsh.

Discussions about games or practices away from the sport setting (e.g., car ride home) were generally viewed positively by the children in the harmonious dyads and appraised negatively by children in the conflicted dyads. Although the car ride home has not been studied among parent-coaches and their children previously, Tamminen et al. (2017) examined this context among non-coach parents and their children. They found that some participants experienced the car ride home as something to endure while others seemed to truly enjoy the car ride, seeing it as a valuable an opportunity to debrief with their parents. Our study sheds some light on why contexts such as the car ride home may be appraised differently, suggesting that it may be tied to broader aspects of the parent-coach and daughter relationship. The results of the current study would further suggest it is necessary to examine the broad spectrum of interactions between parent-coaches and their children across settings, rather than focus on certain settings in isolation.

\section{Strengths and Limitations}

Strengths of this study included the 
participation of children, which is important because some previous studies have only included parent-coaches (e.g., Elliott \& Drummond, 2017; Kerins et al., 2017). The focus on father-coaches and their daughters was another strength, adding to previous work that has focused on fathers or parents coaching boys (e.g., Elliott \& Drummond, 2017; Kerins et al., 2017; Weiss \& Fretwell, 2005). The use of a dyadic analysis (Jowett et al., 2007) enabled us to provide a nuanced account for similarities and differences between two types of father-coach and daughter relationships.

A limitation of this study was that we did not observe father-coach-daughter relationships. For example, observations of team practices would have provided more insights into the behaviors father-coaches displayed toward their daughters, and may have been particularly useful for understanding more about differential treatment of daughters to avoid perceptions of favoritism. The study also relied on single interviews, and relatively short interviews with the daughters. Follow-up interviews could have provided participants with opportunities for further reflexive elaboration of the themes presented.

Multiple interviews (e.g., over the course of a season) could have revealed information about changes in the father-coach and daughter relationship. Dyadic social processes fluctuate, both short-term (e.g., daily) and over longer periods of time, and interactions between pairs of social actors are fluid (Felmlee, 2007). Furthermore, research among couples in romantic relationships shows that changes can be predicted by factors outside of the dyad (Ferrer \& Rast, 2017). Understanding more about changes in parent-coach dyads over time, and how factors outside of the dyad (e.g., competition results, teammate interactions) may influence the relationship would shed more light on the ways in which parents and children experience the dual parent-coach role. Finally, this study should be considered as an exploration of father-coach and daughter relationships, and the profiles presented should be subjected to further examination and analysis.

\section{Implications}

Rather than discourage parent-coaches (as suggested by some sport organizations; e.g., BC Soccer Premier League, 2012), given that parent-coaches are essential to youth sport, a more realistic approach would be to educate parent-coaches on productive ways in which they can interact with their own children. Practical implications - which may both inform the development of parent-coach educational initiatives and be of interest to parent-coaches themselves - arise from the key factors that appeared to differentiate between the harmonious and conflicted dyads. For instance, a key differentiator between the dyads was the coaching approach of the father-coach. Hence, an applied implication for father-coaches themselves could be to adopt a more relational coaching approach. Father-coaches could also adopt autonomy supportive parenting 
approaches. Furthermore, consistency between father-coach behaviors in sport and home settings appeared to be important in the harmonious dyads. Finally, rather than treating their own children 'more harshly' (as in the conflicted dyads), father-coaches could consider more sophisticated approaches to avoid perceptions of favoritism (e.g., carefully managing starting roles and playing time depending on the opposition). Employing such strategies may help improve relationships between father-coaches and their daughters.

Representatives of sport organizations have expressed the need for more research on parent-coaches. Using the results of the current study as a starting point, it may be possible to create parent-coach education training modules, whether informally at a local (club) level or as part of more formal coach education at a broader sport organization level. It is important that parent-coach education goes beyond simple codes of conduct or 'do's and don'ts' lists, which has a limited impact on behavior (Elliot \& Drummond, 2015). For example, it would be possible to use the descriptions provided in this study to create vignettes or examples that could be used to form the content of coach education initiatives. Coach education for parent-coaches could also incorporate contemporary approaches to leadership such as transformational leadership, which involves behaviors that are designed to empower, inspire, and challenge athletes (Turnnidge \& Côté, 2018). Furthermore, such edu- cational approaches should be tailored to age and stage of athlete development (Côté \& Gilbert, 2009). This may be particularly valuable as there is currently a dearth of research testing and evaluating theoretically driven, interpersonal-focused, coaching interventions in youth sport (Turnnidge \& Côté, 2018).

In conclusion, by adopting a dyadic analytic approach, two types of father-coach and daughter relationships were presented (harmonious and conflicted). Certain factors (e.g., coaching approach, consistency between sport and home settings) appeared to differentiate between the harmonious and conflicted dyads. These findings offer a contribution to the literature by moving beyond broad ideas that parent-coaching is associated with both positive and negative outcomes. Rather, they show that there are features that can make the father-coach and daughter relationship more positive and harmonious. The results of the current study would suggest there is merit in continuing to examine the types and nature of relationships between parent-coaches and their children. In particular, it would be useful to know more about the short- and long-term consequences of harmonious versus conflicted father-coach and daughter relationships. 


\section{References}

Amorose, A. J., Anderson-Butcher, D., Newman, T. J., Fraina, M., \& Iachini, A. (2016). High school athletes' self-determined motivation: The independent and interactive effects of coach, father, and mother autonomy support. Psychology of Sport and Exercise, 26, 1-8. https://doi.org/10.1016/j. psychsport.2016.05.005

BC Soccer Premier League. (2012). Technical operations manuscript. https:// mufc. ca/wp-content/uploads/2017/05/ BCSPL-Technical-Operations-Manual-2012.pdf?x11453\#: :targetTex$\mathrm{t}=\mathrm{It} \% 20$ is $\% 20$ recommended $\% 20$ where $\% 20$ parent,are $\% 20$ responsible $\% 20$ for $\% 20$ is $\% 20$ avoided.

Berger, R. (2015). Now I see it, now I don't: Researcher's position and reflexivity in qualitative research. Qualitative Research, 15(2), 219-234. https:/ / doi.org/10.1177/1468794112468475

Côté, J., \& Gilbert, W. (2009). An integrative definition of coaching effectiveness and Expertise. International Journal of Sports Science \& Coaching, 4(3), 307-323. https://doi. org/10.1260/174795409789623892

Eliasson, I. (2018). Child-rearing in public spaces: The challenging dual-role relationships of parent-coaches and child-athletes of coaches in Swedish team sports. Sport, Education, and Society, 24(9), 1006-1018. https://doi.org/ 10.1080/13573322.2018.1528219

Elliott, S. K., \& Drummond, M. (2017). The experience of parent/coaches in youth sport: A qualitative exploration of junior Australian football. Journal of Amateur Sport, 3(3), 64-85. https:// doi.org/10.17161/jas.v3i3.6511

Feldman, R. (2012). Bio-behavioral synchrony: A model for integrating biological and microsocial behavioral processes in the study of parenting. Parenting, 12(2-3), 154-164. https:// doi.org/10.1080/15295192.2012.683 342

Felmlee, D. H. (2007). Application of dynamic systems analysis to dyadic interactions. In A. D. Ong \& M. H. M. van Dulmen (Eds.), Series in positive psychology. Oxford handbook of methods in positive psychology (pp. 409-422). Oxford University Press.

Ferrer, E., \& Rast, P. (2017). Partitioning the variability of daily emotion dynamics in dyadic interactions with a mixed-effects location scale model. Current Opinion in Behavioral Sciences, 15, 10-15. https://doi.org/10.1016/j. cobeha.2017.05.005

Gagne, M. (2003). Autonomy support and need satisfaction in the motivation and well-being of gymnasts. Journal of Applied Sport Psychology, 15(4), 372-390. https://doi. org/10.1080/714044203

Grolnick, W. S., Ryan, R. M., \& Deci, E. L. (1991). Inner resources for school achievement: Motivational mediators of children's perceptions of their parents. Journal of Educational Psychology, 83(4), 508-517. https://doi. org/10.1037/0022-0663.83.4.508 Harwood, C. G., \& Knight, C. J. (2015). Parenting in youth sport: A position paper on parenting expertise. 
Psychology of Sport and Exercise, 16(1), 24-35. https://doi.org/10.1016/j. psychsport.2014.03.001

Holt, N. L., Jørgensen, H., \& Deal, C. J. (2021). How do sport parents engage in autonomy-supportive parenting in the family home setting? A theoretically informed qualitative analysis. Journal of Sport \& Exercise Psychology, 43, 61-70. https://doi.org/10.1123/ jsep.2020-0210

Holt, N. L., \& Knight, C. J. (2014). Parenting in youth sport: From research to practice. Routledge.

Holt, N. L., Pankow, K., Tamminen, K. A., Strachan, L., MacDonald, D. J., Fraser-Thomas, J., Côté, J., \& Camiré, M. (2018). A qualitative study of research priorities among representatives of Canadian Provincial Sport Organizations. Psychology of Sport and Exercise, 36, 8-16. https://doi.org/10.1016/j. psychsport.2018.01.002

Imenda, S. (2014). Is there a conceptual difference between theoretical and conceptual frameworks? Journal of Social Sciences, 38(2), 185-195. https:// doi.org/10.1080/09718923.2014.118 93249

Jowett, S., \& Arthur, C. (2019). Effective coaching: The links between coach leadership and coach-athlete relationship_-From theory to research to practice. In M. H. Anshel, T. A. Petrie, \& J. A. Steinfeldt (Eds.), APA bandbooks in psychology series. APA bandbook of sport and exercise psychology, Vol. 1. Sport psychology (pp. 419-449). American Psychological Association. https://doi. org $/ 10.1037 / 0000123-022$
Jowett, S., Timson-Katchis, M., \& Adams, R. (2007). Too close for comfort? Dependence in the dual role of parent/coach-child/athlete relationship. International Journal of Coaching Science, 1, 59-78. https://www.researchgate.net/ publication/288898947_Too_close_ for_comfort_Dependence_in_ the_dual_role_of_parentcoach-childathlete_relationship

Kerins, A., Ferandez, M., \& Shinew, K. (2017). Parent coaches' experiences and insights into a youth soccer program. Journal of Amateur Sport, 3(1), 50-78. https://doi.org/10.17161/jas. v0i0.5870

Knight, C. J., Boden, C. M., \& Holt, N. L. (2010). Junior tennis player's preferences for parental behaviors. Journal of Applied Sport Psychology, 22(4), 377-

391. https://doi.org/10.1080/104132 00.2010 .495324

Knight, C. J., Neely, K. C., \& Holt, N. L. (2011). Parental behaviors in team sports: How do female athletes want parents to behave? Journal of Applied Sport Psychology, 23 (1), 76-92. https:// doi.org/10.1080/10413200.2010.525 589

Lincoln, Y. S., Lynham, S. A., \& Guba, E. G. (2018). Paradigmatic controversies, contradictions, and emerging confluences, revisited. In N. K. Denzin \&Y. S. Lincoln (Eds.), The SAGE bandbook of qualitative research (5th ed., pp. 213263). Sage.

Lippold, M. A., Davis, K. D., Lawson, K. M., \& McHale, S. M. (2016). Day-to-day consistency in positive parent-child interactions and youth 
well-being. Journal of Child and Family Studies, 25(12), 3584-3592. https:/ / doi.org/10.1007/s10826-016-0502-x Littlefield, R. S., \& Larson-Casselton, C. (2009). Coaching your own child: An exploration of dominance and affiliation in parent-child communication in the public sphere. In T. J. Socha \& G. H. Stamp (Eds.), Communication series. Parents and children communicating with society: Managing relationships outside of home (pp. 189-206). Routledge.

Maccoby, E. E. (1999). The uniqueness of the parent-child relationship. In W. A. Collins \& B. Laursen (Eds.), Relationships as developmental contexts: The Minnesota symposia on child psychology (Vol. 30, pp. 157-175). Lawrence Erlbaum Associates.

McCarthy, P. J., \& Jones, M. V. (2007). A qualitative study of sport enjoyment in the sampling years. The Sport Psychologist, 21, 400-416. https://doi. org/10.1123/tsp.21.4.400

Miles, M. B., \& Huberman, A. M. (1994). Qualitative data analysis: An expanded sourcebook. Sage.

Miles, M. B., Huberman, A. M., \& Saldaña, J. (2014). Qualitative data analysis: A methods sourcebook ( $3^{\text {rd }}$ ed.). Sage.

Milne, J., \& Oberle, K. (2005). Enhancing rigor in qualitative description: A case study. Journal of Wound Ostomy \& Continence Nursing, 32(6), 413-420. https://doi.org/10.1097/00152192200511000-00014

Neergaard, M. A., Olesen, F., Andersen, R. S., \& Sondergaard, J. (2009). Qualitative description - the poor cousin of health research? BMC Medical Re- search Methodology, 9(52). https://doi. org/10.1186/1471-2288-9-52

Patton, M. Q. (2002). Qualitative research and evaluation methods ( $3^{\text {rd }} \mathrm{ed}$.). Sage.

Pynn, S. R., Dunn, J. G. H., \& Holt, N. L. (2019). A qualitative study of exemplary parenting in competitive female youth team sport. Sport, Exercise, and Performance Psychology, 8(2), 163-178. https://doi.org/10.1037/spy0000141

Reeves, C. W., Nicholls, A. R., \& McKenna, J. (2009). Stressors are coping strategies among early and middle adolescent Premier League Academy soccer players: Differences according to age. Journal of Applied Sport Psychology, 21(1), 31-48. https://doi. org/10.1080/10413200802443768

Rubin, H. J., \& Rubin, I. (2012). Qualitative interviewing: The art of hearing data (3rd ed.). Sage.

Sandelowski, M. (2000). Whatever happened to qualitative description? Research in Nursing and Health, 23(4), 334340. https://doi.org/10.1002/1098240X(200008)23:4<334::AIDNUR9>3.0.CO;2-G

Sandelowski, M. (2010). What's in a name? Qualitative description revisited. Research in Nursing \& Health, 33(1), 77-84. https://doi.org/10.1002/ nur.20362

Schmid, O. N., Berstein, M., Shannon V. R., Rishell, C., \& Griffith, C. (2015). "It's not just your dad, it's just your coach..." The dual-relationship in female tennis players. The Sport Psychologist, 29(3), 224-236. https:/ / doi. org/10.1123/tsp.2014-0049 
Shields, P. M., \& Rangarajan, N. (2013). A playbook for research methods: Integrating conceptual frameworks and project management. New Forums Press.

Tamminen, K. A., Poucher, Z. A., \& Povilaitis, V. (2017). The car ride home: An interpretive examination of parent-athlete sport conversations. Sport, Exercise, and Performance Psychology, 6(4), 325-339. https://doi.org/10.1037/ spy0000093

Thorne, S., Kirkham, S. R., MacDonald-Emes, J. (1997). Interpretive description: A noncategorical qualitative alternative for developing nursing knowledge. Research in Nursing \& Health, 20(2), 169-177. https://doi.org/10.1002/(sici)1098240x(199704)20:2<169::aidnur9>3.0.co;2-i

Trussel, D. E., (2016). Young people's perspectives of parent volunteerism in community youth sport. Sport Management Review, 19(3), 332342. https://doi.org/10.1016/j. smr.2015.09.001
Turnnidge J., \& Côté, J. (2018). Applying transformational leadership theory to coaching research in youth sport: A systematic literature review. International Journal of Sport and Exercise Psychology, 16(3). 327-342. https://doi.org/10. 1080/1612197X.2016.1189948

Vella, S. A., \& Perlman, D. J. (2014). Mastery, autonomy and transformational approaches to coaching: Common features and applications. International Sport Coaching Journal, 1(3), 173-179. https://doi.org/10.1123/iscj.20130020

Weiss, M. R., \& Fretwell, S. D. (2005). The parent-coach/child-athlete relationship in youth sport. Research Quarterly for Exercise and Sport, 76(3), 286-305. https://doi.org/10.1080/02 701367.2005.10599300

Zehntner, C., McMahon, J., \& McGannon, K. R. (2019). An intensive longitudinal investigation of a parent-coach's practices and strategies 'in action'; challenge and opportunities. Sports Coaching Review. https://doi.org /10.1080/21640629.2019.1590082 